\title{
Factors Associated with the Use of E-learning Systems in Selected State Universities of Colombo District.
}

\author{
M.U Kiriwandarage \\ Department of Information Technology, CINEC, Millennium Drive, IT Park, Malabe, Sri Lanka. \\ maduwanthi.uthpala@cinec.edu
}

\begin{abstract}
The swift development of internet technology had made a remarkable impact on learning. Technology has been used as a tool to support thE-learning. Electronic learning (E- learning) is considered as the main component of this techno oriented learning infrastructure. The purpose of $\mathrm{E}$ - learning programs is to facilitate and assess the learning with the support of communication technology. Compared to the last decade, students are now using Elearning for their studies. Though E-learning is highly used in higher education, some drawbacks can be seen in implementing and maintaining of E- learning programs. Those drawbacks are reducing the productivity of learning. Therefore, it is essential to identify the factors which are associated with E-learning and then to implement Elearning systems. The aim of this article is to identify the factors associated with the use of E-learning.
\end{abstract}

Keywords: Electronic learning, deficiencies, factors

\section{INTRODUCTION AND LITERATURE STUDY}

With the advancement of ICT, E-learning is becoming the most significant recent development in the field of education. Most universities nowadays develop and are planning to develop E-learning programs in order to fulfill the large amount of distance learning requirements. E-Learning also supports the access to learning resources, communication facilities, assessment facilities, administrative and student support. Therefore most of the Sri Lankan universities especially State universities are now very much interested on E-learning projects. The Government of Sri lanka has allocated funds in order to fulfill this requirement.

Several educators have considered E-learning as the newest development of distance education. E-learning provides more active and synchronous learning by using interactive technology (Choi et al.,2008). According to Harman, \& Kulkarni (2007), E-learning is having the ability to improve the quality of learning, improve access to education, reduce the cost of education and improve the cost effectiveness of education. E-learning can be considered as the most popular learning tool in modern education. Therefore, it is highly used in universities, as students finds it more reliable to work with. Electronic learning provides several benefits to modern education. It provides unique opportunities to students, who have limited access to training and education. E-learning associates with new and creative methods to guide and provide unique access to information resources.

Several researchers have conducted various studies to identify the success factors associated with the Use of Elearning. Govindasamy (as cited in Selim,2007) is one of the researchers, who discussed the learning quality.

Most of Sri Lankan students are now enrolling in government or foreign universities to gain a degree after school education. E-learning is highly used in Sri Lankan higher education nowadays due to its interactivity and effectiveness. As a part of E-learning, distant learning is now also becoming a popular learning method. The Quality Assurance and Accreditation Council also known as QAAC(as cited in Suraweera,2011) had recommended that it should "“"take necessary Phases to commence e-learning courses for both internal and external students ("Subject Review Report: Department of Library and Information Science," 2008). The QAAC, is a part of UGC Sri Lanka, which serves to enhance the quality of Information education. 
TABLE I

BATTERFIE'S MODEL

\begin{tabular}{|c|c|}
\hline Type of Dimension & Associated factor \\
\hline \multirow[t]{3}{*}{ Learner Dimension } & $\begin{array}{l}\text { Learner attitudes towards } \\
\text { computers }\end{array}$ \\
\hline & Learner computer anxiety \\
\hline & Learner Internet self-efficiency. \\
\hline \multirow[t]{2}{*}{ Instructor Dimension } & Instructor attitudes \\
\hline & Instructor responses timeline \\
\hline \multirow[t]{2}{*}{ Course dimension } & E-Learning course flexibility \\
\hline & E-Learning course quality \\
\hline \multirow[t]{2}{*}{ Technology dimension } & Technology quality \\
\hline & Internet quality. \\
\hline \multirow[t]{2}{*}{ Design dimension } & Perceived usefulness \\
\hline & Perceived ease \\
\hline
\end{tabular}

QAAC named quality benchmarks such as good institutional support, proper course structure, traditional classroom learning methods such as face to face learnings, written exams, tutorials, laboratory practices.

Volery and Lord (as cited in Selim,2007) identified three factors associated with the use of E-learning. Researchers had randomly selected about 200 university students for the survey and identified most related aspects for Online education. Finally, Volery and Lord had identified several factors. Those were technology (including ease of access, interface design and level of interaction), Instructor (attitudes towards students, instructor technical competence and classroom interaction), and previous experience of using technology.

The Study used deductive approach, as it is based on a proved theory and narrows down to a more specific hypothesis to test. The existing theory plays a major role, as it encourages to develop research hypothesis and variables.

Theory $\longrightarrow$ Hypothesis $\longrightarrow$ Observation

\section{B. Quantitative Approach}

Quantitative approach has been used for the study. Characteristics of the sample were analyzed numerically. Each variable was assigned a weighted value and then
Bhattacherjee(2001) had done a study on success of Elearning. He had used randomly selected sample and conducted the study using both qualitative and quantitative approaches. Based on the results, expectation and confirmation model was derived. The model describes the learners 'satisfaction with E-learning by discussing six dimensions. Those dimensions are student dimension, instructor dimension, course dimension, technology dimension, design dimension, and environment dimension. Under those six dimensions, thirteen factors are identified listed in Table 1.

\section{METHODOLOGY}

\section{A. General Objective}

This paper uses data from undergraduate students from selected state universities in Colombo district. The general objective of this paper is to find out the factors which are associated with the use of E-learning in selected state universities. The general objective is categorized to following specific objectives;

\section{B. Specific Objectives}

To identify Personal factors associated with the use of Elearning

To identify Academic factors associated with the use of E-learning

To identify Technical factors associated with the use of E-learning

To identify Social factors associated with the use of Elearning

\section{RESEARCH APPROACH}

\section{A. Research questions}

1. What are the personal factors associated with the use of E-learning?

2. What are the social factors associated with the use of E-learning?

3. What are the academic factors associated with the use of E-learning?

4. What are the technical factors associated with the use of E-learning

Researcher assumed that several factors are associated with the use of E-learning. Researcher made hypothesis based on those assumptions. The study was then carried out to check hypothesis which rejects the null value.

appropriate statistical methods were used to identify the significant association between independent variables and dependent variable. Finally, results were generalized to the population. The size of the population was 859 . The population consisted with internal undergraduate 
students of selected state universities of Colombo district.

\section{Data Description}

Several independent variables were detected under each factor. Use of E-learning is considered as the dependent variable for the study.

\section{Data Collection}

Collection of data was done using a questionnaire.

\section{E. Sampling procedure}

The purposive sampling method was used as the sampling technique. The researcher had found departments of each universities which uses E-learning systems in their studies. From each department total number of students were identified.

\section{F. Data Sources}

The Data source for the research was all the participants of the sample. Also, books, e books, e journals, web sites, reports, subject experts ${ }^{\text {ee }}$ knowledge has been used to find information to the research. verbal statements were also used in order to verify the gathered data.

TABLE II

RESULTS OF BINARY LOGISTICS REGRESSION

\begin{tabular}{|l|r|r|r|}
\hline Variable & \multicolumn{1}{|c|}{ S.E. } & Wald & \multicolumn{1}{c|}{ Sig. } \\
\hline Gender & 0.353 & 0.260 & 0.610 \\
Age & 0.257 & 0.249 & 0.618 \\
Mother & 0.335 & 0.828 & 0.363 \\
tongue & & & \\
University & 0.128 & 4.354 & 0.037 \\
Faculty & 0.135 & 0.063 & 0.802 \\
Academic & 0.189 & 0.587 & 0.443 \\
year & & & \\
IT & 0.268 & 8.019 & 0.005 \\
Background & & & \\
Often of & 0.099 & 0.763 & 0.229 \\
connection & & & \\
System & 0.190 & 6.000 & 0.024 \\
Availability & & & \\
Constant & 2744.190 & 0.000 & 0.996 \\
\hline
\end{tabular}

\section{DATA ANALYSIS}

\section{A. Questionnaire and fact finding}

Data for the study was gathered using a questionnaire. The questionnaire consisted with twenty-two main questions. Among the twenty-two questions, fourteen questions have single answers. Two open ended questions were also added to the questionnaire. questionnaire also consisted of four multiple choice questions. Last two questions were Likert scaled questions.

A pilot survey was conducted, before starting the actual data gathering. It was done to identify the success of the questionnaire. The pilot questionnaire was distributed among eighteen students of the sample. (Student selection for the pilot survey was random). Few changes were made on the questionnaire based on the response rate of the pilot survey. Finalized questionnaire was distributed among the sample.

Data collection process has been taken at selected departments. Collected data was analyzed using SPSS 21. It was noticed that 377 students have submitted their responded questionnaires. Missing values has been detected in submitted questionnaires. Missing values were recoded to the same corresponding variable before starting the data analyzing process. Therefore, missing values are also utilized to the study.

Descriptive analysis was also done on data in order to Analyze the sample. Figure 1 presents the results obtained for Gender.

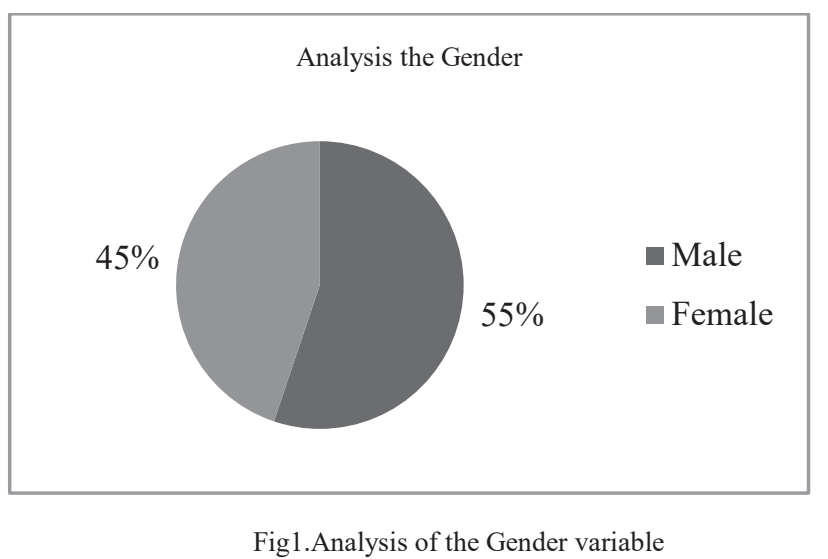

According to the Figure 4.2, most of participants were Male students, by giving $55.00 \%$ responding rate from the total participants. Responding rate of Female participants are $45.00 \%$. No missing values for this question. It was clearly noticed that all participants have responded to this question.

Selection of students for the study was random. Each student was given an equal opportunity for answer 
questions. No favor or no potency given for any students at the time of study.

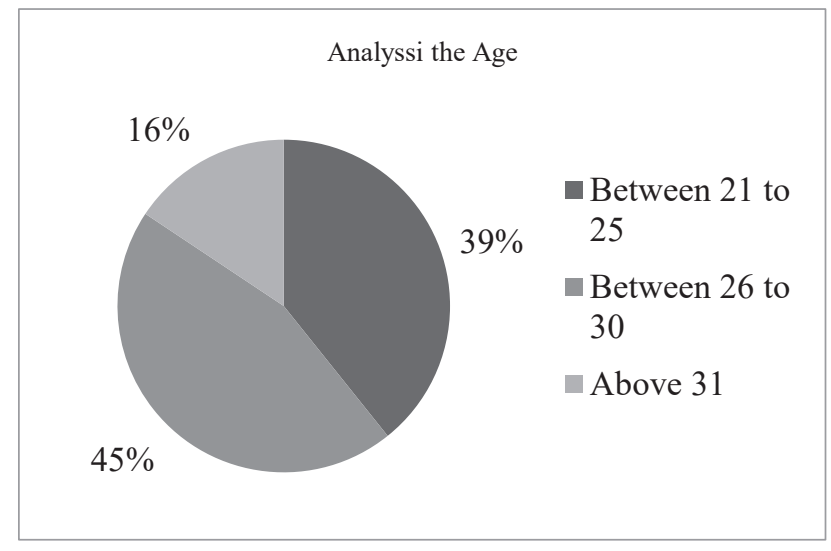

Fig 2 Analysis of the Age

According to results, highest number responses were obtained from 26 to 30 age categories.

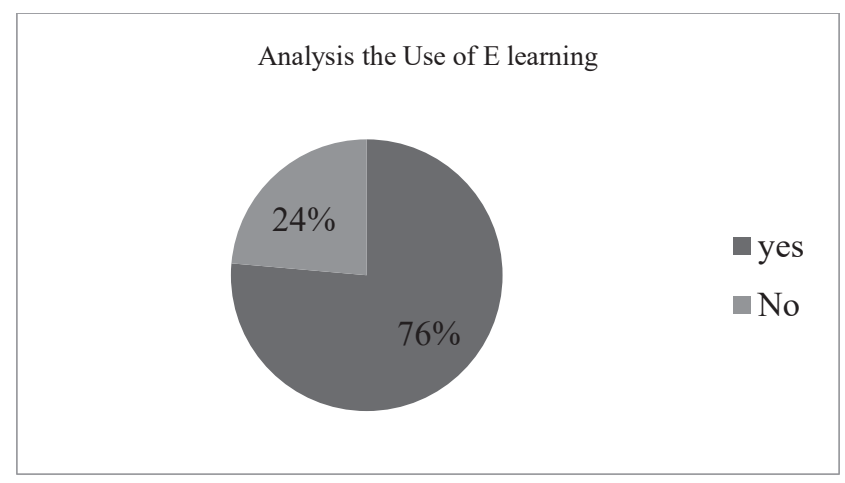

Fig 4 Analysis of the Use of E-learning

According to the Figure 4, 76\% of the sample is using Elearning systems.

Cross tabulation was used to identify the association between independent and the dependent variable.

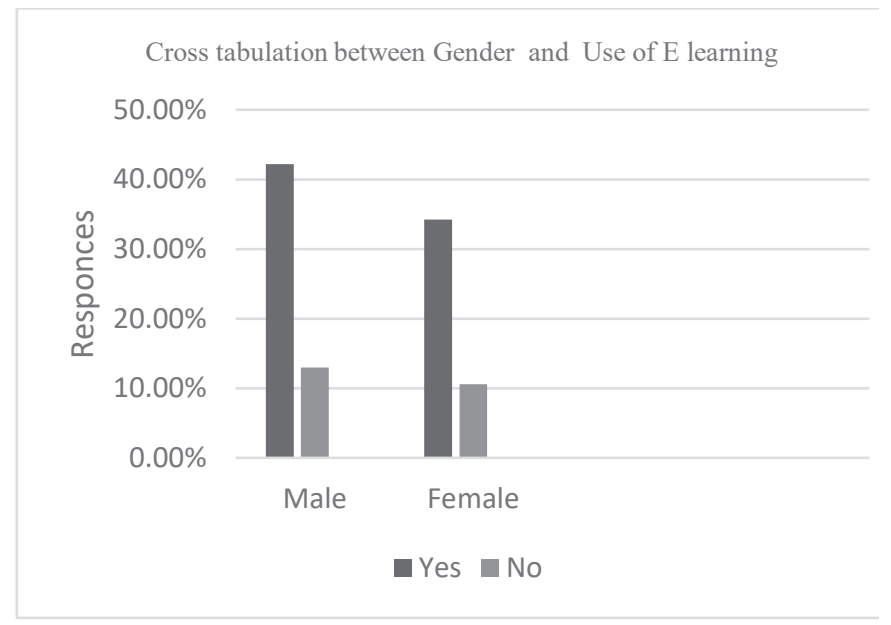

Fig 6 Cross tabulation between Gender and Use of E-learning
According to results, Male students are more interested on using E-learning systems.

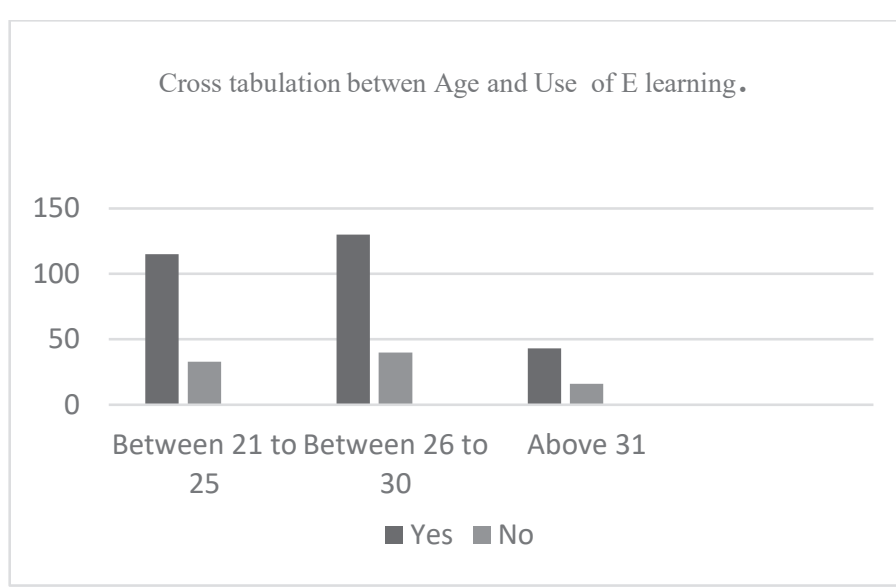

Fig 3. Cross tabulation between Age and use of E-learning.

According to figure 3, students who are in age between 26-30, use E-learning systems than others.

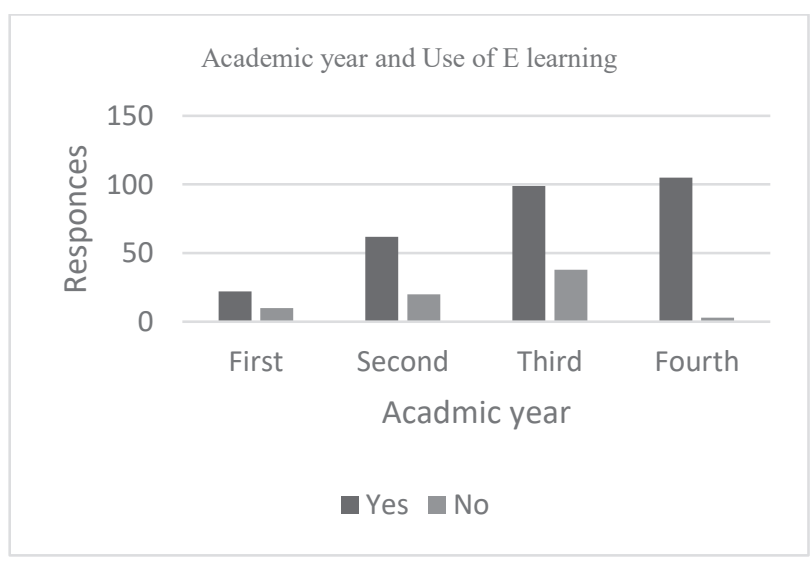

Fig 5. Cross tabulation between Academic year and use of E-learning.

According to the figure 5, fourth year students use E-learning systems than others.

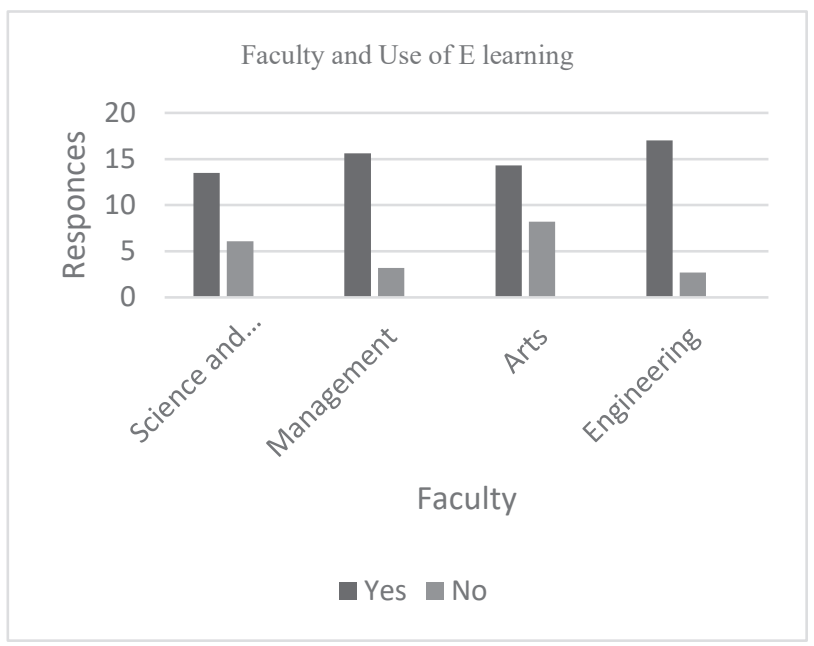


Fig 7. Cross tabulation between Academic year and use of E-learning.

According to the results, Engineering students are highly using E-learning systems.

\section{B. Binary Logistics Regression}

Binary logistic regression analysis was used in the research, as the Dependent variable (use of E-learning) is dichotomous. weighted values were assigned to use of eLearning as follows.

If yes for use of E-learning - 1

Not using E-learning - 0

Each independent variable is tested with the dependent variable to discover a statistical correlation. Results were Tabulated below.

\section{Hypothesis Testing.}

Correlation Analysis was performed to examine each hypothesis. For each hypothesis, null

hypothesis and alternative hypothesis are derived.

\section{Null hypothesis: HO}

\section{Alternative hypothesis: H1}

Hypothesis 1: Use of E-learning is depending on Academic factors

Hypothesis 2: Use of E-learning is depending on Social Factors.

Hypothesis 3: Use of E-learning is depending on Technical Factors

Hypothesis 4: Use of E-learning is depending on Personal factors.

Hypothesis tested during the analysis. Correlation and Binary Logistic Regression analysis was used to discover factors. If a significant value was obtained below 0.05 , the null hypothesis was rejected and decided that there is an association available between independent and dependent variables. Following independent variable were identified as having significant association with the Use of E-learning. Those are,

$\circ$ University- significant value was 0.037

○ IT Background- significant value was 0.005

- System Availability- significant value was 0.024 .

Identified independent variables can be categorized to following factors.

University- Academic
Table 2 shows the results of Standard error, Wald statistic values, and significance value of each independent

variable. The table shows the contribution of each independent variable to the model and statistical significance. The Wald statistic was used to determine the statistical significance of each independent variable to the dependent variable. Significance value was used to determine statistical significance between tested variables. Significance value of University, IT Background and System Availability are less than the 0.05. The Wald statistic value of University, IT Background and System Availability is also more than 1.000. Therefore, University, IT Background and System Availability has a significant correlation to the Use of Elearning.

\section{CONCLUSION}

\section{A. Conclusion of Binary Logistics Regression.}

According to Binary logistics regression, following factors were selected as having a statistical correlation with the use of E-learning.

- University - Significant value obtained was 0.037 , which is smaller than 0.05 .

- IT background- Significant value obtained was 0.037 , which is smaller than 0.05 .

- System availability- Significant value obtained was 0.024 , which is smaller than 0.05 .

Therefore University, IT background and System availability has the significant impact on E-learning systems.

IT Background, System Availability- Technical

B. Conclusion of the Study

The development of new information technologies in the $21 \mathrm{st}$ is rapidly introducing new opportunities in education. It is also creating conditions for the formation of a global informational, educational and cultural space. From this research, the researcher had tried to identify the factors associated with the use of Elearning. ICT seems to have an extreme impact on the process of learning. ICT offers new possibilities for learners and educators. Therefore, ICT directly make an impact on student's performance.

Academic Factor and Technical factors are having significant association with the Use of E-learning. Results of the study shows that use of E-learning systems is highly dependent on 
university and technology. Researcher believes it is worth to identify those factors to enhance the quality of education.

\section{ACKNOWLEDGEMENT}

The research was supported and monitored by the University of Colombo, Sri Lanka. The author wishes to credit all selected State universities of Colombo district, for their tremendous support nurtured throughout this study.

\section{REFERENCES}

[1] H.M. Selim, Critical Success Factors for E-learning Acceptance: ConWrmatory Factor Models. Computers and Education, 49, 396-413 , 2007.

[2]N.Suraweera, E-Learning in Information Management Education in Sri Lanka: An examination of needs and issues, 2001.

[ 3].Choi,S.Lee, J.Kang and Y.Hong, Learning Style and Case-based E-learning (rep.), 2008.

[4] J.Harman and S.Kulkarni, Reliable Reasoning: Induction and Statistical Learning Theory (Jean Nicod Lectures) (Vol. 2), 2007.

[5]A.Batterjie, Understanding Information Systems Continuance: An Expectation-Confirmation Model,2001. 